I think that the authors have expanded their idea in one direction only, and I have not seen any reviews of their books applying this idea in the other direction. If, however, this application has been made, I shall be glad to be referred to the passages containing it.

W. A. T. Hallow ts

New Universily Club, St. Janes's Street, S.W. January 4.

\section{Atmospheric Electricity}

THE traces afforded by the self-registering electroneter at this observatory show that the conditions of the atmospheric electricity at Kew were very similar during the recent frosts to those observed at Montsouris by M. Descroix. We have, however, in the automatic instrument the great advantage of contintous registration, and therefore our information is not limited to the results afforded by seven observations daily.

The whole period of the frost was characterised by extremely bigh tension which with us averaged and frequently exceeded the amount which sufficed to derange the French instrument.

The absolute maximum tension recorded equalled 600 volts, and occurred abcut 4 P.M. on December I6.

The most noticeable feature in the curves of electrical disturb. ance during the period is that of the daily range of the instrument having attained a maxi aum woully between $S$ to $I 0$ P.M., the tension reaching over 400 volts at the time on the $r 7$ th, I 8 the, and 2 ist, and over 500 on the $22 n d$ ult.

The fall in tension on the $25^{\text {th }}$ was irregtiar and the value becane almost zero at 6 A.M. on the 26 th, for the whole of which day it continued low. Negative electricity was recorded for the first time from 1 to 3 A.M. on the 29 th.

Undoubtedly the value of the tension of the atmospheric electricity, as measured by the Thoinson electrometer is, as $M$. Descroix states, only a relative one. We have determined experimentally that with the same instrument the indicated ten. sion is largely infuenced by the distance of the nozzle of the water-dropping collector from the wall of the building in which the instrument is placed, and in accordarce vith a suggestion of Sir W. Thomson, we replace during the passage of thunderstorms our ordinary discharge-tube by a very short one, so as to get the scale of terions within the range of the electrometer.

Kew Observatory, January 6

G. M. Whipple

\section{Electricaliphenomenon}

I HAVE just read in NATURE (vol. xix. p. I82) an account of a strainge electrical phenomenon observed at Teignmouth. In connection witl it the following incident may be of some inzerest:- When in Switzerland, not long since, I made with some friends the ascent of Monte Rosa. The weatber was un ettled, and on gaining the summit we saw a thunderstorm advancing in our direction from the Italian valleys, and not wing to tum ourselves into lightning-conductors we deemed is wise to retire frois the summit. We had retreated a very short distance along the arite when the storim-clouds swept up upon us; the fire snow fell so thick that we could hardly see one another, and we were all suddenly attracted by a peculiar ticking or fizzing from our hair; when I held up my axe the ticking was most distinctly heard from the top of it. The thunder ceaced, and we felt that we were acting as points, through which the ground electricity was flowing off into the cloud; if it had been dark, the bluish light observed at Teign. mouth might have been visible.

As at Teignmouth, so on Monte Rosa; it was freezing hard when the plienomenon was observed.

Alta Terrace, Monkstown, Cork

\section{Time and Longitude}

As the questirns I propounded under this head in NATURE, vol. xviii, p. 40 , bave been argain alluded to by Mr. E. L. Layard, I may remark that they receive a complete answer in the "Geographical Reader," by C. B. Clarke, M.A. (Macmillan aid Co., 1876 ). At p. I9 he says: "At the town of Sitka, in Alaska, half the population are Russians who have arrived from Russia across Asia; half the population are Americans who have arrived riâ the United States. Hence, when it is Sunday with the Russians it is Satuday with the Americans; the Russians are busy on Monday while the Americans are in church on Sunday to the great interruption of business."

It is cvident, then, that our new year first commenced in
Alaska at 9 A.M: Greenwich time on December 31. Each of our days commences at the same hour and lasts forty-eight hours; the year exists for 366 days.

January 4

LATIMER CLARI

\section{Magnetic Storm of May I4, I5}

THE magnetic storm of May 14, I5, which was observed simultaneously in England, China, and Australia, and which made itself felt in the telegraph wires of Persia and India, was also perfectly observed in America. Mr. G. F. Kingston, director of the government observatory at Toronto, Canada, has kindly forwarded to me a tracing of his magnetograms, and I find that all the principal inflexions of the declination, as well as of the components of the intensity, bear a striking resemblance to those recorded at the Stonyhurst observatory. The correspondence between the two vertical force curves on May if is very remarkable for such distant stations. Comparing the times of the principal minimas in the V.F. trace, and of the chief maximum of the declination, we have the following results in Toronto mean time:-

Toronto Observatory

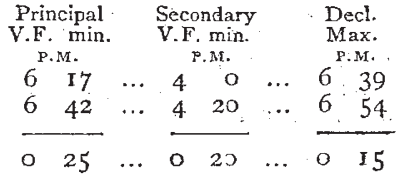

The disturbing force would thus appear to have been felt soinewhat earlier in Canada than in Europe.

The extent of the extreme oscillation of the V.F. magnets camot be compared, as that at Stonyhurst was too sensitive, and was consequently thrown off its balance; but the rapid movement of the declination needle immediately preceding the maximum was almost identical in England and in Canada, the Stonyhurst curves showing a rise of $28^{\prime} 39^{\prime \prime}$ in less than twenty minutes, and that of Toronto an increase of $26^{\prime} 53^{\prime \prime}$ in the same time.

It is important to note that I bave used the terms maximum and minimum in reference to increase and decrease of ordinate, but it so happens that an increase of ordinate signifies a decrease of H.F. and V.F., and also of W. declination in the Toronto curves, whilst it shows an increase of all these elements in the magnetograms of Stonyhurst.

Stonyhurst Observatory, December: $28, \mathbf{1} 878$ S. J. Perry

\section{Blowpipe Experiment}

I BEG to inform you of the following curious results which may be considered of sufficient interest to lead to fuxther investigation of the subject.

Having received a quantity of blowpipe charcoal from Freiberg, about two months ago, I placed two sticks in a "stoneware" jar full of pure water in order to saturate them therewith, so that small squares cut with a saw and placed on aluminium plate as a support, might stand the blowpipe heat longer. I also found that thus treated there is little or no black sawdust, which dirties the hands, \&rc., more than anything else in hlowpipe operations.

Having also placed in the same jar of water two "aluminium spoons" (thick rods about five inches Iong), I was surprised to find that after the charcoal had sunk to the bottom on saturation, the aluminium rods were covered with semi-opaque roundish coystals (part being perfectly transparent) 'near the surface of the water, and also at the very botton where the spoons rested on the: jar.

Thinling the crystals might be due (although I could not tell how with such a deliquescent substance) to some phosphoric acid I had previously fused upon the aluminium spoons, I cleaned them thoroughly and placed them in fresh pure water with the charcoal about a fortright ago, and they are again covered with the same kind of crystals. I now carefully scraped the crystals off the aluminium rods with a penknife and placed them on an agate slab, where, when dry, they had a perfectly white, sugary appearance, with some minute transparent fragments. Taking up some of these opaque white fragments upon a hot bead of boric acid, I submitted them to the action of the blowpipe, and found-

(a) That they at first emitted a slight yellow pyrochrome, so that they could not be duc to postash. 